Check for updates

Cite this: RSC Adv., 2017, 7, 33843

Received 14th May 2017

Accepted 26th June 2017

DOI: $10.1039 / \mathrm{c} 7 \mathrm{ra05437h}$

rsc.li/rsc-advances

\section{Facile fabrication of hierarchical porous carbon based on extract separated from coal with outstanding electrochemical performance}

\begin{abstract}
Peng Chang ${ }^{a}$ and Zhihong Qin (D) *ab
Due to the abundant accessible pores for ion storage, hierarchical short diffusion paths for ion transport, and high diffusion efficiency through macropores, newly developed hierarchical porous carbons (HPCs) have been attracting much attention as one of the most promising electrode materials for highperformance supercapacitors. However, the large-scale production and practical applications of HPCs are still big challenges. Herein, a novel kind of HPCs were directly synthesized from low-cost extracts of coal by coupling nano $\mathrm{MgO}$ template with in situ $\mathrm{KOH}$ activation strategy. During the formation of HPCs, nano-MgO not only serves as structure-directing agent to obtain nanosheet structure, but also plays a critical role in determining the porous system and rate performance of HPCs. The HPCs feature interconnected layered structure with developed hierarchical pore system, and have a high specific surface area up to $3347 \mathrm{~m}^{2} \mathrm{~g}^{-1}$. As electrodes for supercapacitors, the HPCs show a high capacitance of $346 \mathrm{~F} \mathrm{~g}^{-1}$ at $0.5 \mathrm{~A} \mathrm{~g}^{-1}$ in $6 \mathrm{M} \mathrm{KOH}$, an excellent rate performance with capacitance remaining at $262 \mathrm{~F}$ $\mathrm{g}^{-1}$ at $10 \mathrm{~A} \mathrm{~g}^{-1}$ and a superior cycle stability with $92 \%$ capacitance retention after 5000 cycles at $5 \mathrm{~A} \mathrm{~g}^{-1}$. The fine capacitive performances of HPCs are ascribed to hierarchical pore system, short paths for ion fast transport and 2D layered graphene sheets, make it a promising electrode candidate for high performance supercapacitors.
\end{abstract}

\section{Introduction}

Due to the increasingly limited availability of fossil fuel resources, the sustainable energy storage devices that can effectively store and release the electrical energy have drawn considerable attention with the increased demand for the efficient utilization of clean energy resources. Meanwhile, supercapacitors have been recognized as a novel kind of promising energy storage devices in recent years in view of their attractive characteristics such as superior rate capability, high power density, and long cycle life., ${ }^{\mathbf{1} 2}$

Generally, the electrochemical properties of supercapacitors largely depend on the electrode materials. ${ }^{3,4}$ Various kinds of carbon materials have been adopted as electrode materials for supercapacitors, such as hierarchical porous carbons (HPCs), graphene, carbon nanotubes, carbon fibers, and mesoporous carbons..$^{5-9}$ Among those electrochemical active materials, HPCs have been considered as a promising electrode candidate for supercapacitors and deeply investigated owing to their large surface area, electrochemical stability, high conductivity, and low cost. ${ }^{10}$

${ }^{a}$ School of Chemical Engineering and Technology, China University of Mining \& Technology, Xuzhou 221116, P. R. China

${ }^{b}$ Key Laboratory of Coal Processing and Efficient Utilization (Ministry of Education), Xuzhou 221116, P. R. China. E-mail: qinzh1210@163.com
It is widely known that the existence of micropores is directly responsible for the charge storage to obtain a high specific capacitance while the reasonable meso-/macropores could serve as electrolyte reservoirs and favorable paths which is helpful for fast ion transportation. ${ }^{11-14}$ The synergetic effect of unique micro-/meso/macro hierarchical pore system could impart HPCs with superior capacitive property and rate capability in supercapacitor applications. ${ }^{15}$ Therefore, the HPCs have been attracting much attention as one of the most promising electrode materials for high-performance supercapacitors due to their huge advantage in unique porosity and it is necessary to develop an efficient method for production of HPCs with ideal porous structure.

Coal as the most affordable energy resource currently being consumed worldwide, is cheap and abundant, and also has been commonly used as carbon source. Up to now, template techniques have been widely employed to synthesize HPCs with well-defined pore characteristics. ${ }^{\mathbf{1 6}, 17}$ However, the intrinsic mineral matters in raw coal can also serve as the template and cause the collapse of expectant porous structure during the process of acid washing. ${ }^{18}$ In a general way, high ash coal was treated with aqua regia, cationic surfactant or $\mathrm{NH}_{4} \mathrm{OH}$ to remove the ash content. ${ }^{19}$ Nevertheless, these procedures are complicated, time-consuming and high cost. Thus, we introduce a creative extraction and back-extraction method to obtain the desired ash-free group component-loose medium 
component (LMC) from raw coal and adopt it as the carbonaceous precursor for synthesis of HPCs. ${ }^{2021}$ What's more, the LMC primarily consists of abundant aliphatic hydrocarbons and aromatic hydrocarbons. During the pyrolysis process, aromatic hydrocarbon molecules featuring $\mathrm{sp}^{2}$-hybridized carbon atoms could polymerize and aromatize into large interconnected thin layered nano-structure like graphene due to the nanospace confinement of layered template.

Herein, we report a nano layered $\mathrm{MgO}$ template strategy coupled with in situ $\mathrm{KOH}$ activation to synthesize HPCs from LMC which was separated from raw coal. The electrochemical properties of the electrodes prepared from HPCs for supercapacitors were investigated. $\mathrm{MgO}$ template plays a critical role in determining the porous structure and electrochemical performance of HPCs and the morphological character could be effectively adjusted via the changing of template proportion.

\section{Experimental}

\subsection{Preparation of loose medium component}

All chemicals in this experiment were purchased from Aladdin without further purification. Tongting Huaibei raw coal in China was pulverized to pass through a 200 mesh sieve for use. First, $200 \mathrm{~g}$ pre-treated coal sample and a mixed extraction agent of $10 \mathrm{~L} \mathrm{~N}$-methyl-2-pyrrolidone (NMP) and $10 \mathrm{~L} \mathrm{CS}_{2}$ were added into extraction kettle and stirred for $3 \mathrm{~h}$. After the extraction process, $20 \mathrm{~L}$ deionized water used as back extractant was added into extraction kettle and stirred for $40 \mathrm{~min}$. Then, the back-extraction liquor was layered after standing for $3 \mathrm{~h}$. The lower dark layer was $\mathrm{CS}_{2}$ layer while the upper layer was water and NMP layer. At last, LMC was obtained by centrifugation of upper layer liquor at a speed of $6000 \mathrm{rpm}$ for $20 \mathrm{~min}$ and the yield was about $17 \%$. The proximate and ultimate analyses of raw coal and LMC are listed in Table 1 and the TEM images, infra-red spectrum, and thermogravimetric analysis of LMC have been published in our previous works. ${ }^{20,21}$

\subsection{Preparation of HPCs}

In a typical run, LMC, nano $\mathrm{MgO}$ and $\mathrm{KOH}$ were ground respectively, and mixed in mortar with a mass ratio of $1 / 1 / 6$. The resultant mixture was then activated at $750{ }^{\circ} \mathrm{C}$ for 1 hour under nitrogen stream in a tube furnace and the temperature was controllably ramped at a heating rate of $5{ }^{\circ} \mathrm{C} \mathrm{min}{ }^{-1}$. The HPC-1 was obtained by washing with $1 \mathrm{M} \mathrm{HCl}$ and deionized water repeatedly to remove the template and reaction products. The

Table 1 Proximate and ultimate analyses of raw coal and LMC

\begin{tabular}{|c|c|c|c|c|c|c|c|c|c|}
\hline \multirow[b]{2}{*}{ Sample } & \multicolumn{4}{|c|}{ Proximate analysis (wt\%) } & \multicolumn{5}{|c|}{ Ultimate analysis (wt\%) } \\
\hline & $\mathbf{M}_{\mathrm{ad}}$ & $A_{d}$ & $\mathrm{~V}_{\mathrm{daf}}$ & $\mathrm{FC}_{\text {daf }}$ & $\mathrm{C}_{\mathrm{daf}}$ & $\mathrm{H}_{\mathrm{daf}}$ & $\mathrm{O}_{\mathrm{daf}}^{a}$ & $\mathrm{~N}_{\mathrm{daf}}$ & $\mathrm{S}_{\mathrm{t}, \mathrm{daf}}$ \\
\hline Raw & 1.27 & 24.20 & 24.94 & 75.06 & 86.50 & 5.05 & 6.32 & 1.47 & 0.66 \\
\hline LMC & 0.48 & 2.21 & 27.53 & 75.63 & 84.72 & 5.20 & 6.72 & 2.59 & 0.77 \\
\hline
\end{tabular}

${ }^{a}$ By difference; $\mathbf{M}_{\mathrm{ad}}$ : moisture (air dried base); daf: dry and ash-free base; $A_{d}$ : ash (dry base); $V_{d a f}$ : volatile matter (dry and ash-free base); $\mathrm{S}_{\mathrm{t}, \mathrm{daf}}$ : total sulfur (dry and ash-free base). resulting products were termed as HPC- $X$ respectively, where $X$ is the ratio of $\mathrm{MgO} / \mathrm{LMC}$. For comparison, several ratios of $\mathrm{MgO} /$ LMC were evaluated: $0,1,3,5$, and 6 with other conditions remaining unchanged. In addition, HPC-0K, HPC-3K samples with the $\mathrm{LMC} / \mathrm{MgO} / \mathrm{KOH}$ mass ratio of $1 / 5 / 0,1 / 5 / 3$, respectively were also prepared under the same conditions to explore the effect of $\mathrm{KOH}$ dosage on the porous structure.

\subsection{Characterization of HPCs}

The porous properties of HPCs were characterized by $\mathrm{N}_{2}$ adsorption/desorption isotherms at $77 \mathrm{~K}$ with an Autosorb-1-MP analyzer (Quantachrome, USA). The specific surface area $\left(S_{\mathrm{BET}}\right)$ was determined according to the BET (Brunauer-EmmettTeller) method and the pore size distribution was evaluated by the density functional theory (DFT) method in the calculation model of $\mathrm{N}_{2}$ at $77 \mathrm{~K}$ on carbon (slit pore, NLDFT equilibrium model) from the desorption branches of the isotherms. The total pore volume $\left(V_{\mathrm{t}}\right)$ was estimated from the single point adsorption at $P / P_{0}=0.995$. The micropore volume $\left(V_{\text {mic }}\right)$ was reckoned by the calculation from the HK (Horvath-Kawazoe) model, whereas the non- $V_{\text {mic }}$ was calculated from the difference of $V_{\mathrm{t}}$ and $V_{\text {mic }}$. The average pore size $\left(D_{\text {ap }}\right)$ was identified by the equation of $D_{\text {ap }}=4 V_{\mathrm{t}} / S_{\mathrm{BET}}$. The microstructures of HPCs and $\mathrm{MgO}$ were analyzed by transmission electron microscopy (TEM, FEI Tecnai $\mathrm{G}^{2}$ F20, USA) and scanning electron microscopy (SEM, FEI Quanta TM 250, USA). The Raman spectra of HPCs were measured on a Raman spectroscopy (Bruker Senterra, Germany) with an excitation wavelength at $532 \mathrm{~nm}$.

\subsection{Preparation and electrochemical test of HPCs electrodes}

The electrode materials were prepared by mixing $85 \mathrm{wt} \%$ of HPCs, $10 \mathrm{wt} \%$ of acetylene black, and $5 \mathrm{wt} \%$ of polytetrafluoroethylene (PTFE), and then pressed into a thin disk at $5 \mathrm{MPa}$. The resultant carbon thin disk was pressed onto nickel foam at $5 \mathrm{MPa}$ for $5 \mathrm{~min}$ to make supercapacitor electrode. The electrochemical properties of HPCs were investigated using twoelectrode cell, while all the electrochemical tests were operated at room temperature using an electrochemical workstation (Ivium Vertex, Holland). The electrolyte was a $6 \mathrm{M} \mathrm{KOH}$ aqueous solution and before the electrochemical tests, the electrodes were soaked in electrolyte for $12 \mathrm{~h}$. The button-type supercapacitor was assembled with two electrodes with the similar

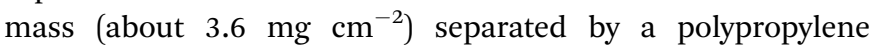
membrane. The cyclic voltammetry (CV) curves were recorded over a range of $0-1 \mathrm{~V}$ at the sweep rate from 1 to $100 \mathrm{mV}$ and galvanostatic charge-discharge (GCD) measurements were performed at various current densities ranged from 0.5 to $10 \mathrm{~A}$ $\mathrm{g}^{-1}$ with a potential window of $0-1 \mathrm{~V}$. Electrochemical impedance spectroscopy (EIS) measurements were conducted with an amplitude of $5 \mathrm{mV}$ over a frequency of $100 \mathrm{kHz}$ to $0.001 \mathrm{~Hz}$. The gravimetric capacitance of the HPCs electrode, $\mathrm{C}\left(\mathrm{F} \mathrm{g}^{-1}\right)$, could be calculated from the galvanostatic discharge process according to the following equation: $C=2 I \Delta t / m \Delta V$, where $I$ is the discharge current (A), $\Delta V$ is the usable voltage after the $I R$ drop (V), $\Delta t$ is the discharge time (s), and $m$ is the mass of active material $(\mathrm{g})$. In addition, the energy density $\left(E, \mathrm{~W} \mathrm{~h} \mathrm{~kg}{ }^{-1}\right)$ and 
power density $\left(P, \mathrm{~W} \mathrm{~kg}^{-1}\right)$ of the supercapacitors were determined by the following equations: $E=C \Delta V^{2} /(2 \times 3.6), P=$ $3600 E / \Delta t$, respectively.

\section{Results and discussion}

\subsection{Physical characterizations of HPCs}

Fig. 1a-d show the SEM images of the prepared HPCs. It is interesting that under the same magnification, the HPCs possess completely different morphologies with the different dosage of nano MgO template. As displayed in Fig. 1a, HPC-1 shows a rough block pattern with some irregular large holes of a few microns on the outside surface which may be induced by the effusion of pyrolysis gas. In Fig. 1b, HPC-3 presents an unordered sponge-like foam structure and the pore size is mostly in the range of 100-300 $\mathrm{nm}$. While the morphology of HPC-5 manifests a typical layered stacking structure with many small nanosheets and macropores, as provided in Fig. 1c. In the case of HPC-6, the sheet-like structure becomes more integral and homogeneous due to the strict space limitation effect led by excessive template addition. In addition, as marked in each figure, there are a large number of macropores with diameter around $200 \mathrm{~nm}$ in HPCs which are inherited from $\mathrm{MgO}$ particles. Because the grinding can hardly meet the requirement of mixing uniformly, many macropores could be formed by the remove of stacked and overlapped nano template via acid washing. In addition, these macropores can also function as ion-buffering reservoirs to shorten the ion transport distance. Meanwhile, this common feature can not only directly and naturally manifest the developed porous structure of HPCs, especially the part of macropores but also embody hierarchical pore system combined with following pore size distribution analysis. Besides, obviously, the morphology of HPCs can be efficiently adjusted by changing the template dosage. Along with the increase of $\mathrm{MgO}$ addition, unordered sponge-like foam structure gradually turns into regular lamellar structure indicating that nano $\mathrm{MgO}$ also plays a role of structure-directing during the preparation of HPCs.

Fig. 1e is the TEM image of nano-MgO, in which many sheetlike $\mathrm{MgO}$ particles with the size of about $30 \mathrm{~nm}$ can be clearly seen. While the TEM observation of HPC-5 (Fig. 1f) reveals a thin and rough layer with abundant ordered micro- and slit mesopores which may be caused by the interlocking of small thin layers or the MgO template embedded vertically on LMC. The big aspect ratio and ideal ratio of micro/mesopores are favorable for ion adsorption and allow fast ion transport across the electrodes which always results in high specific capacitance by forming ion transport expressways. Furthermore, the thin graphene-like sheets are expected to improve the rate performance due to the shortened transport distance of ions.
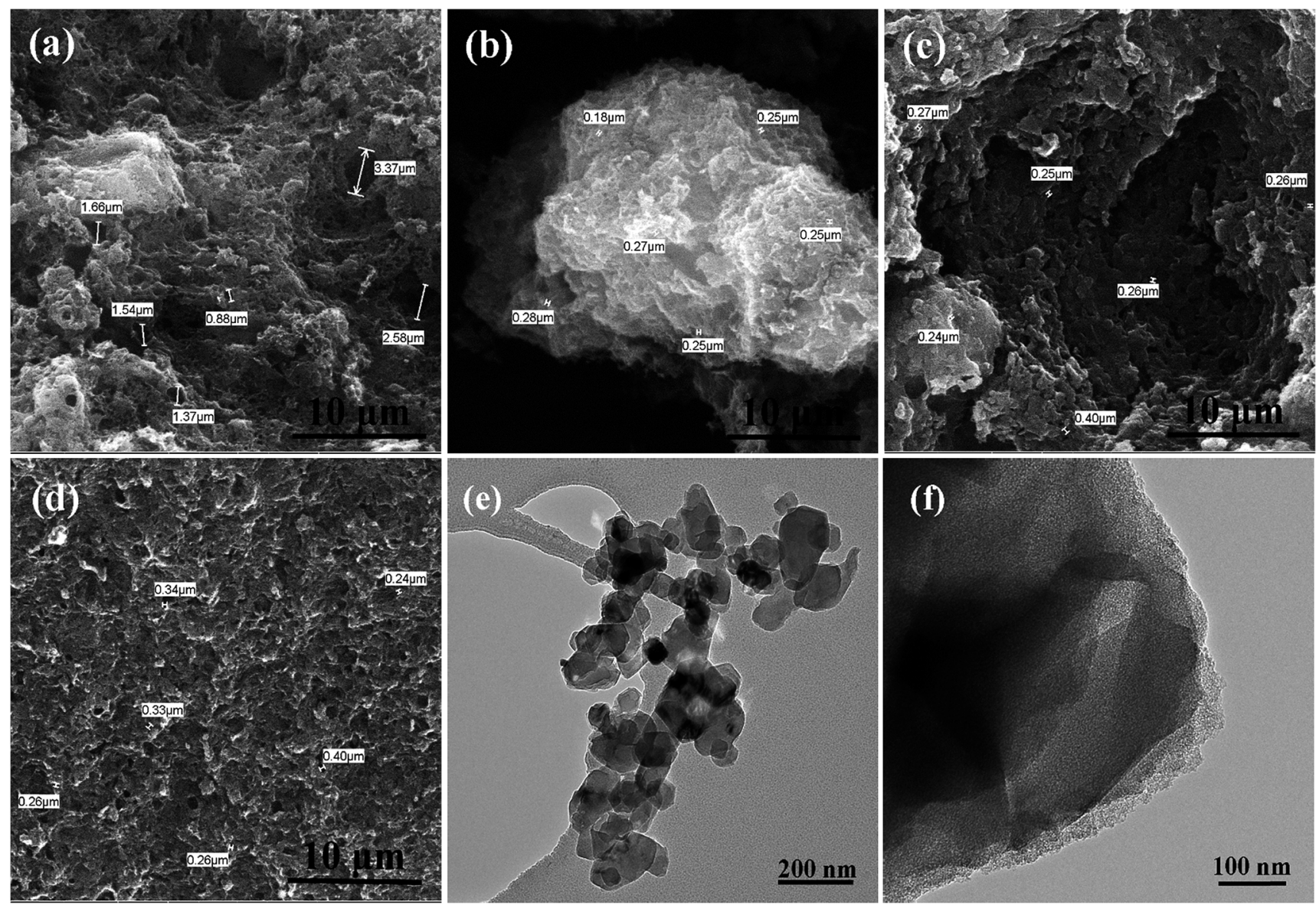

Fig. 1 SEM images of (a) HPC-1, (b) HPC-3, (c) HPC-5, (d) HPC-6; TEM images of (e) nano MgO and (f) HPC-5. 
For comparison, the pure porous carbon (HPC-0) without nano $\mathrm{MgO}$ was also be fabricated, indicative of honeycomb-like structure with many large holes induced by the effusion of pyrolysis gas (Fig. 2a). The HPC-0K under identical conditions in the absence of $\mathrm{KOH}$ was also prepared, in which the relatively thick and stacked sheet-like structure can be clearly observed in Fig. 2b. While, the HPC-3K shows a similar morphology with HPC-5. This also implies the structure-directing effect of nano$\mathrm{MgO}$ during the formation of the HPCs and further confirms the space confinement function of template to create a large number of macropores on HPCs.

Based on the SEM and TEM images in Fig. 1 and 2, we can conceive the schematic of the preparation process of HPCs from LMC, as shown in Fig. 3. Firstly, the mixture of LMC and $\mathrm{KOH}$ particles was uniformly dispersed on the layered $\mathrm{MgO}$ templates. During the annealing process, LMC with high content of aromatic hydrocarbon became soften and melted, and the aromatic hydrocarbon molecules were hold together by the polymerization reactions of active free radicals, and then folded the layered $\mathrm{MgO}$ leading to the interconnected thin layered structure of HPCs. In the meantime, the developed hierarchical pore system was created due to the in situ activation of the embedded $\mathrm{KOH}$ on the formed nano carbon layers and the space confinement effect of MgO template. Finally, the HPCs were obtained after removing the template via acid washing.

The detailed porous properties of HPCs were characterized by nitrogen sorption technique. The $\mathrm{N}_{2}$ adsorption/desorption isotherms and pore size distributions calculated by the DFT method are shown in Fig. 4 and summarized in Table 2. For HPC-0, HPC-1 samples, the adsorption-desorption isotherms exhibit typical characteristics of highly microporous carbon materials, owing to the steep increase of nitrogen adsorption at relative pressure $\left(P / P_{0}\right)$ less than 0.1 which implies the welldeveloped microporosity and the absence of hysteresis loop at higher $P / P_{0}$. As for HPC-3, HPC-5, HPC-6, and HPC-3K, the isotherms reveal combined characteristics of type I and type IV with a $\mathrm{H} 4$ type hysteresis loop. It is worth noting that except for the distinct increase in $\mathrm{N}_{2}$ uptake occurs at $P / P_{0}$ less than 0.1 , the obvious hysteresis loop at $0.4<P / P_{0}<0.7$ assigns to the capillary condensation in small-sized mesopores (smaller than $5 \mathrm{~nm}$ ), suggesting the existence of abundant micropores and mesopores. However, it can also be found that HPC-0K possesses a very underdeveloped microporous structure due to the absence of $\mathrm{KOH}$ which can effectively create abundant micropores and high surface area via the reaction with carbon matrix: $6 \mathrm{KOH}+2 \mathrm{C} \rightarrow 2 \mathrm{~K}+3 \mathrm{H}_{2}+2 \mathrm{~K}_{2} \mathrm{CO}_{3}$. Besides, compared with the HPC-0, the sharp rise of the $\mathrm{N}_{2}$ isotherms for HPC-3, HPC-5, HPC-6, HPC-0K, and HPC-3K at a relatively high $P / P_{0}$ from 0.9 to 1.0 indicates a great deal of large mesopores and macropores inherited from $\mathrm{MgO}$ particles which could facilitate rapider ion mobility and higher charge-discharge rate. ${ }^{22}$ These results are also supported by above SEM images.

From Fig. 4b, we can see that all samples present multimodal distribution centered at $1.2,1.5,1.7,2.5$, and $4 \mathrm{~nm}$. By comparing the pore size distributions of HPC-0K, HPC-3K, and HPC-5, it can be concluded that these abundant micro- and small mesopores are generated from the $\mathrm{KOH}$ activation. The micropores and mesopores of HPC-0, HPC- 1 are much less than HPC-3, HPC-5, and HPC-6. There are more mesopores in HPC-5 in comparison to HPC-3 and HPC-6, while in the field of micropores, HPC-3, HPC-5, and HPC-6 have the similar distribution characteristics. This illustrates that the addition of nano $\mathrm{MgO}$ promotes the formation of micropores and small mesopores because the thin layered structure induced by the structure-directing effect of $\mathrm{MgO}$ template is conducive to the $\mathrm{KOH}$ etching reaction, evidenced by the TEM images in Fig. 1. But superfluous template addition may hinder the contact and reaction between $\mathrm{KOH}$ and LMC, like HPC-6.

As shown in Table 2, along with the increase of $\mathrm{MgO}$ addition, $S_{\text {BET }}$ and $V_{\text {mic }}$ both gradually increase because the layered structure led by the structure-directing effect of $\mathrm{MgO}$ template could contribute to the homogeneous dispersion and reaction of $\mathrm{KOH}$ and avoid the over-reaction. As we all know, the in situ $\mathrm{KOH}$ activation to the thin carbon sheets is much easier than the activation of $\mathrm{KOH}$ to the cluster of carbon particles. In addition, as for HPC-6, the undue MgO dosage lowers the relative content of activation agent which eventually causes the drops of $S_{\mathrm{BET}}$ and $V_{\text {mic }}$. The HPC-5 possesses the highest specific surface area of $3347 \mathrm{~m}^{2} \mathrm{~g}^{-1}$, the $V_{\text {mic }} / V_{\text {non-mic }}$ value of 2.9 , indicating a high extent of reactions and an ideal ratio of micro/mesopores which could generate promising electrochemical performance. Meanwhile, for HPC-0, HPC-3K, and HPC-5, the $S_{\mathrm{BET}}$ increases from 641 to $3347 \mathrm{~m}^{2} \mathrm{~g}^{-1}$ while the $\mathrm{KOH} / \mathrm{LMC}$ mass ratio increases from 0 to 6 with other conditions remaining unchanged, demonstrating the positive effect of in situ $\mathrm{KOH}$ activation on the creation of high surface area and developed pore system.
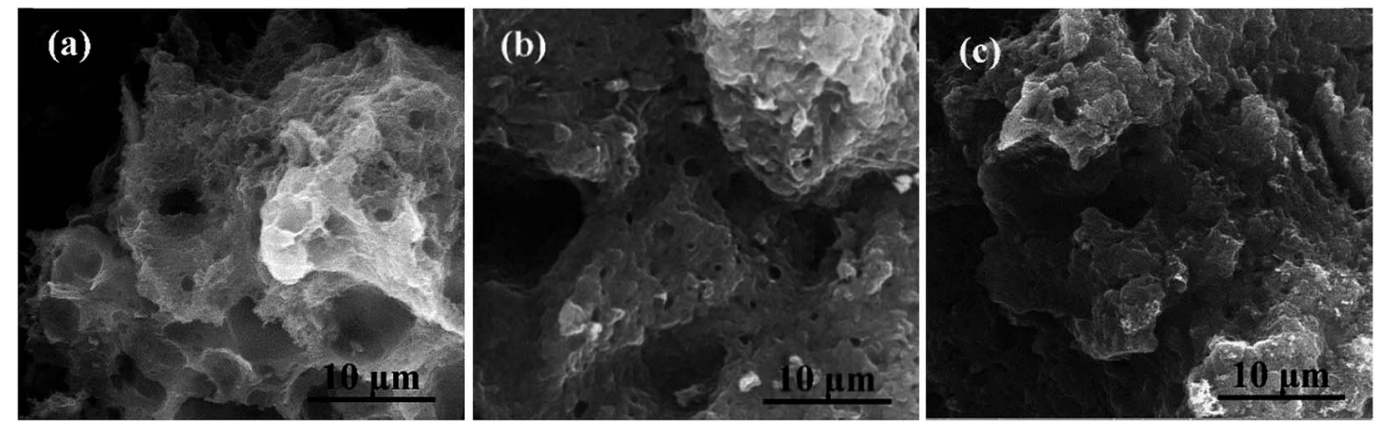

Fig. 2 SEM images of (a) HPC-0; (b) HPC-OK; (c) HPC-3K. 

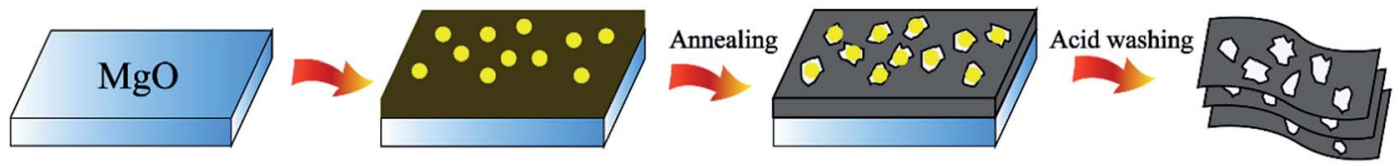

$\mathrm{LMC}$ and $\mathrm{KOH}$ on $\mathrm{MgO}$

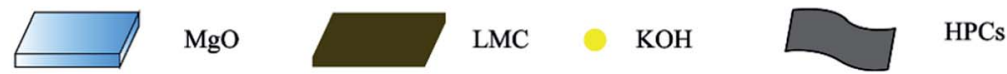

Fig. 3 Schematic of direct preparation process of HPCs from LMC.
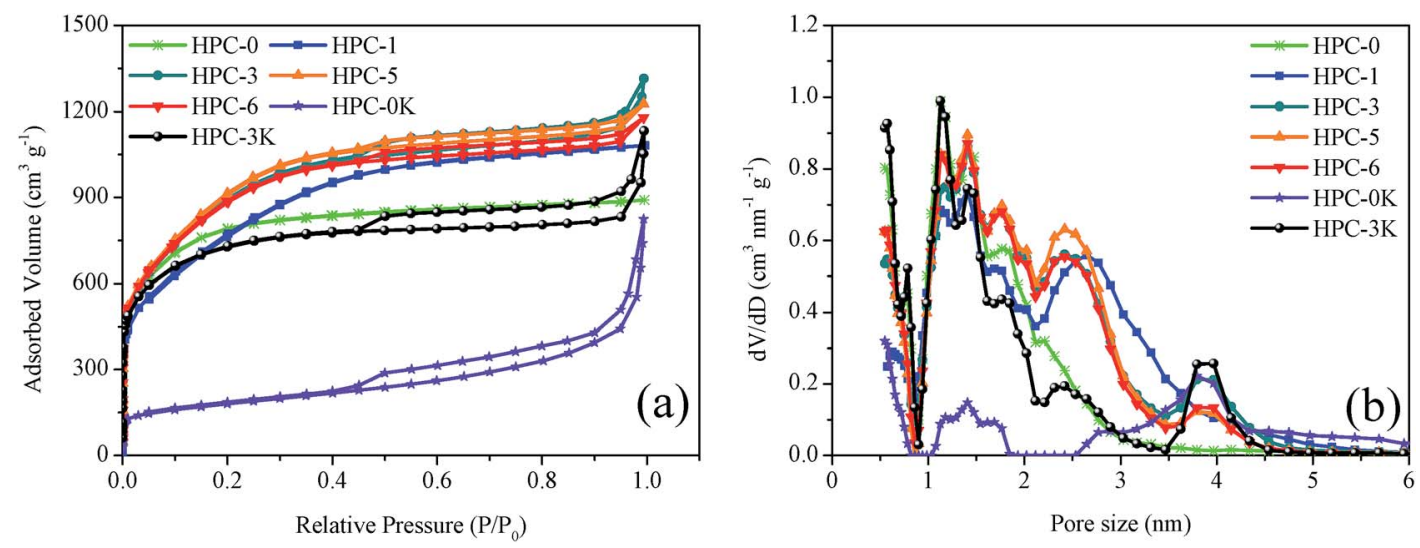

Fig. 4 (a) Nitrogen adsorption/desorption isotherms; (b) pore size distribution of HPCs.

Raman spectroscopy was applied to further analyse the graphitic character of the as-prepared HPCs. As shown in Fig. 5, Raman spectra of HPCs present two apparent Raman-active bands at $1330 \mathrm{~cm}^{-1}$ (D-band) associated with a doubleresonance effect of amorphous carbonaceous structure, and $1590 \mathrm{~cm}^{-1}$ (G-band) which corresponds to the graphite $\mathrm{sp}^{2}$ bonded carbon atoms in-plane vibrations with $\mathrm{E}_{2 \mathrm{~g}}$ symmetry, reflecting the disordered and ideal graphitic lattice respectively. ${ }^{23-25}$ A rise in the number of partial lattice defects owing to abundant pores would bring about an increase in the intensity of the D-band and a concomitant drop in the intensity of the Gband. In this paper, the HPCs possess similar porous structure, thus, the peak intensity ratio $\left(I_{\mathrm{D}} / I_{\mathrm{G}}\right)$ could be used as an indication of the degree of graphitic structural order. ${ }^{21}$ The $I_{\mathrm{D}} / I_{\mathrm{G}}$ of HPC-5 is only 0.83 , indicative of a high graphitization degree which is expected to improve the electrochemical behaviors. This result is in well accordance with the TEM observation and $\mathrm{N}_{2}$ absorption results.
Fig. $6 \mathrm{a}$ is the $\mathrm{CV}$ curves of all samples at $10 \mathrm{mV} \mathrm{s}^{-1}$. The good quasi-rectangular shapes without obvious redox peaks for all HPCs signify the predominant charge storage mechanism in HPCs to be electric double-layer capacitive behavior. It can also be found that both of the $\mathrm{MgO}$ dosage and $\mathrm{KOH}$ addition can lead to the enhancement of integral area and a better quasirectangular shape which mean the larger capacitance. And the effect of $\mathrm{KOH}$ addition is even more visible because the existence of micropores is directly responsible for the charge storage to obtain a high specific capacitance. Meanwhile, the CV curve of HPC-5 exhibits the largest current response and integral area among HPC samples, suggesting the highest capacitance at a relatively low scan rate. Fig. $6 \mathrm{~b}$ shows the $\mathrm{CV}$ curves of HPC-5 at different scan rates. HPC-5 exhibits sustained capacitive behaviors with plateau regions for $\mathrm{CV}$ curves at low scan rates, proving the efficient formation of perfect electrical double layers due to the reversible adsorption and desorption of the electrolyte ions in the micropores. It can also be observed that,

Table 2 The porosity parameters of HPCs

\begin{tabular}{llllcc}
\hline Sample & $S_{\text {BET }}\left(\mathrm{m}^{2} \mathrm{~g}^{-1}\right)$ & $V_{\text {total }}\left(\mathrm{cm}^{3} \mathrm{~g}^{-1}\right)$ & $V_{\text {mic }}\left(\mathrm{cm}^{3} \mathrm{~g}^{-1}\right)$ & $V_{\text {non-mic }}\left(\mathrm{cm}^{3} \mathrm{~g}^{-1}\right)$ \\
\hline HPC-0 & 2574 & 1.241 & 1.037 & 0.204 & 1.893 \\
HPC-1 & 2790 & 1.674 & 1.101 & 0.573 & 2.399 \\
HPC-3 & 3261 & 1.774 & 1.274 & 0.500 & 2.175 \\
HPC-5 & 3347 & 1.773 & 1.321 & 0.452 & 2.118 \\
HPC-6 & 3223 & 1.694 & 1.269 & 0.425 & 2.102 \\
HPC-0K & 641 & 0.857 & 0.265 & 0.592 & 5.348 \\
HPC-3K & 2659 & 1.473 & 1.085 & 0.388
\end{tabular}




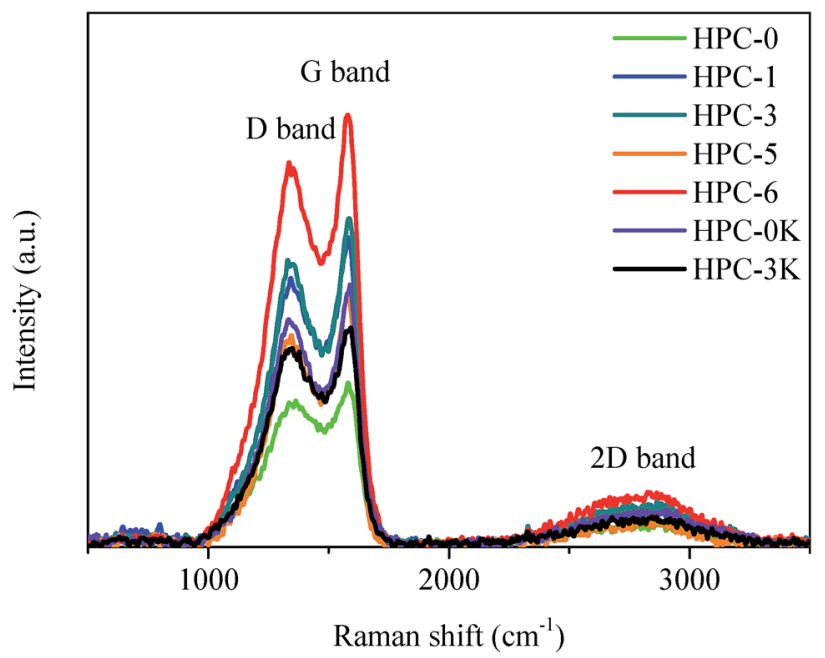

Fig. 5 Raman spectra of HPCs.

at a high scan rate, the mismatch between the diffusion rate of electrolytes and charge transfer speed directly leads to the slight deviation from rectangular shape that implies the relatively poor accessibility of electrolyte ions into electrode surface and finally results in the reduction of charging efficiency and a lessened capacitance.

The capacitance values of HPCs at increasing current loads (from 0.5 to $10 \mathrm{~A} \mathrm{~g}^{-1}$ ) were calculated from GCD curves and plotted in Fig. 6c. It can be observed that the discharge capacity goes through a remarkable decay with the increase of current density because of the limited diffusion on the electrode surface. ${ }^{26}$ The fading rate of HPC-5 possesses the slowest pace of which the specific capacitance reaches $346 \mathrm{~F} \mathrm{~g}^{-1}$ at $0.5 \mathrm{~A} \mathrm{~g}^{-1}$ and retains $262 \mathrm{~F} \mathrm{~g}^{-1}$ at $10 \mathrm{~A} \mathrm{~g}^{-1}$ with a capacitance retention of $76 \%$, showing the highest capacitance and best rate performance, which may be due to structure merits of developed hierarchical pore system and short paths for ion fast transport on 2D thin graphene-like carbon sheets. Besides, compared with other HPC- $X$, we can find that MgO template plays an active role on the rate performance of electrodes, especially at high current density, owing to the reduced charge transfer resistance which should be ascribed to short paths for ion fast transport provided by the graphene sheets. Moreover, the enhancement of $\mathrm{KOH}$ addition can offer more micropores which can directly enhance the specific capacitance of HPCs, as proved by the contrasts among HPC-0K, HPC-3K, and HPC-5.

Fig. 6d presents the Ragone plots of HPCs in $6 \mathrm{M} \mathrm{KOH}$ aqueous electrolyte, calculated from the charge-discharge data. It can be found that the energy densities of HPCs drop with the rise of average power densities, which means that less energy can be released at higher rate. As the power density noticeably increases from 921 to $3155 \mathrm{~W} \mathrm{~kg}^{-1}$ at the current density interval of 0.5 to $5 \mathrm{~A} \mathrm{~g}^{-1}$, the energy density of HPC-5 slowly reduces from 39 to $16 \mathrm{~W} \mathrm{~h} \mathrm{~kg}^{-1}$. These results confirm that synergetic effect of developed micro-/meso/macro hierarchical pore system and unique interconnected layered structure can be effectively utilized for charge storage and hint that the asprepared HPC-5 has the satisfying prospects in the electrochemical devices.

The enhanced kinetics for ion transport and charge transfer in HPCs can be directly proved by Nyquist plots, as illustrated in
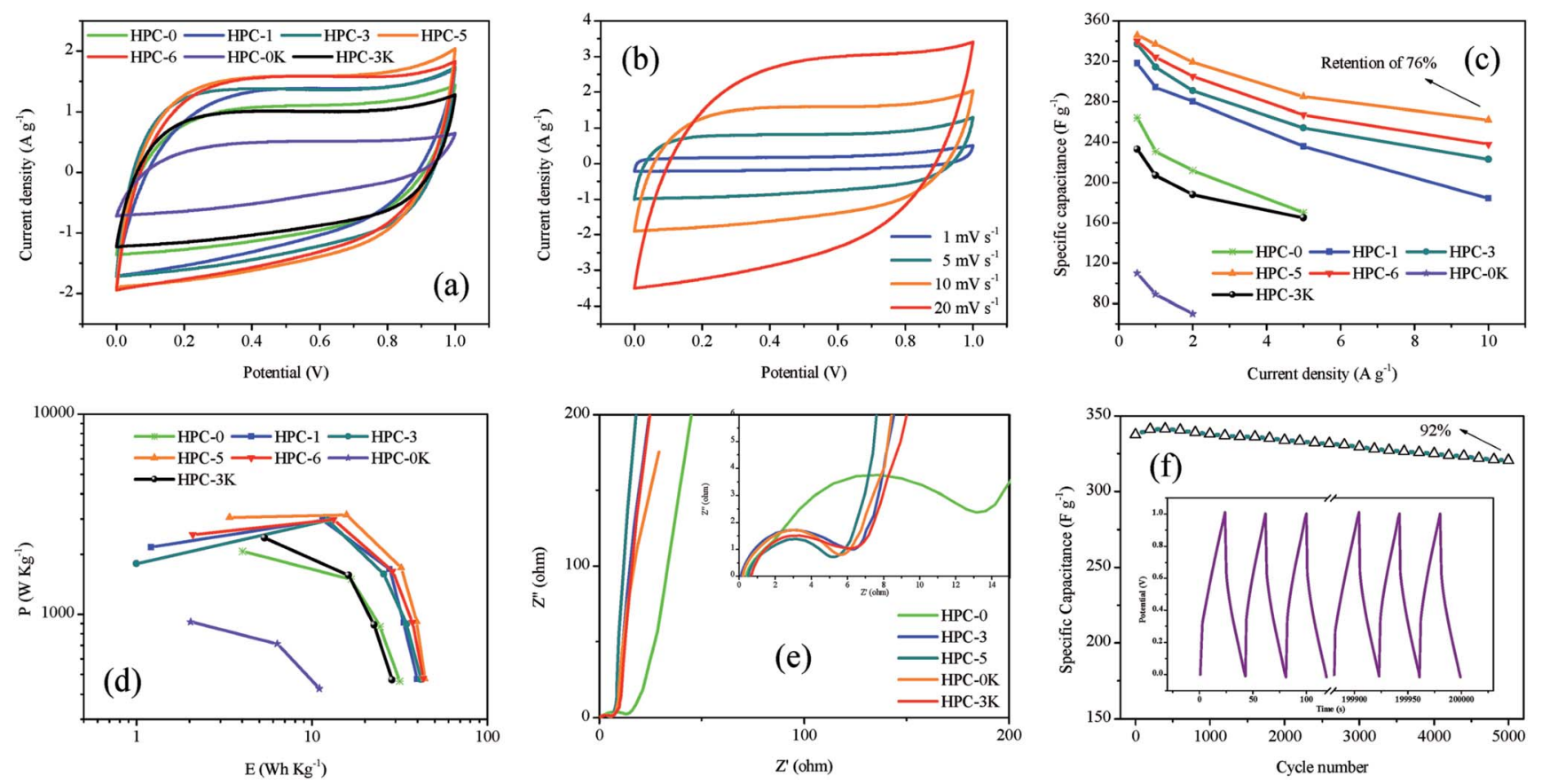

Fig. 6 (a) CV curves of HPCs at $10 \mathrm{mV} \mathrm{s}^{-1}$; (b) CV curves of HPC-5 at different scan rates; (c) specific capacitance of HPCs at different current densities; (d) Ragone plots of HPCs; (e) Nyquist plots of HPCs; (f) cycle stability of HPC-5 measured at $5 \mathrm{~A} \mathrm{~g} \mathrm{~g}^{-1}$ (inset shows the initial and last 3 cycles of charge-discharge curves). 
Fig. 6e. The diameter of semicircle curve in high frequency area gradually decreases with the increase of nano $\mathrm{MgO}$ dosage, demonstrating the lower charge transfer resistance which should be attributed to short paths for ion fast transport and enhanced electrical contact on graphene sheets. Furthermore, it is noteworthy that along with the increase of $\mathrm{KOH}$ addition, the linear trend in low frequency region becomes more ideal as a result of the well-developed microporosity which are directly responsible for the charge storage to form a high specific capacitance. These results are also in accordance with the above mentioned capacitive performance and CV curves. As for HPC-5, the low real axis $(x)$ intercept $(0.5 \mathrm{ohm})$, small diameter of the semicircle, short length of the slope segment, and nearly vertical line along the imaginary axis indicate that HPC-5 possesses low equivalent series resistance, charge transfer resistance, ions diffusion resistance, and good conductivity, excellent pore accessibility for the electrolytes, which usually further lead to high specific capacitance. ${ }^{27}$

Fig. $6 f$ exhibits the long-term cycling stability of HPC-5, showing an excellent capacity retention of about $92 \%$ over 5000 charge-discharge cycles at $5 \mathrm{~A} \mathrm{~g}^{-1}$. As shown in the inset of Fig. 6f, the galvanostatic charge-discharge curves still remain triangular shape without obvious pseudocapacitance behavior after 5000 cycles which is the typical characteristic of ideal supercapacitors. The outstanding cycling stability of HPC-5 should be partly ascribed to the combined effect of ideal hierarchical pore system which functions as active sites and expressways for ion adsorption and fast ion transport, and the interconnected lamellar structure with the advantages of high conductivity and structural stability for HPC-5.

The electrochemical performance of HPCs fabricated in this paper has been further compared with other carbon materials without hierarchical structure reported in literature. ${ }^{21,28-36}$ Obviously, the specific capacitance and rate performance of HPC-5 are both superior to most of the reported work, as shown in Fig. 7, indicating the great promising of the synthesized HPCs as electrode materials for high performance supercapacitors.

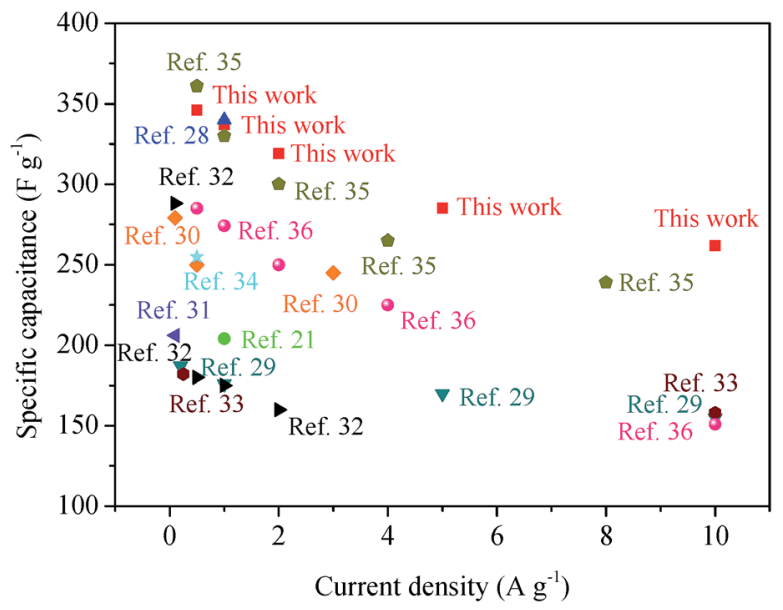

Fig. 7 Comparison of specific capacitance and current density of HPC-5 with other electrodes in aqueous electrolytes.

\section{Conclusions}

In summary, a novel kind of HPCs has been successfully prepared from the ash-free group component separated from raw coal by extraction and back-extraction method through layered nano $\mathrm{MgO}$ template strategy coupled with in situ $\mathrm{KOH}$ activation. The results show that, during the annealing process, aromatic hydrocarbons in LMC polymerized and transformed into interconnected thin layered structure due to the structuredirecting effect of nano-MgO. Meanwhile, the space confinement function of $\mathrm{MgO}$ template to create a large number of macropores and the positive effect of in situ $\mathrm{KOH}$ activation on the formation of high surface area and developed pore system during the preparation of HPCs have both been demonstrated. Specifically, HPC-5 sample exhibits high specific capacitance of $346 \mathrm{~F} \mathrm{~g}^{-1}$ in $6 \mathrm{M} \mathrm{KOH}$ aqueous electrolyte, good rate capability of $262 \mathrm{~F} \mathrm{~g}^{-1}$ at $10 \mathrm{~A} \mathrm{~g}^{-1}$ and superior cycling stability with $92 \%$ of capacitance retention after 5000 cycles at $5 \mathrm{~A} \mathrm{~g}^{-1}$. Such excellent electrochemical performance should be assigned to the synergistic effect of unique micro/meso/macro hierarchical pore system, short paths for ion fast transport and 2D layered graphene sheets. Benefited from above great capacitive behaviors and the low cost high ash coal as precursor, the prepared novel hierarchical porous carbon materials present great potential for practical application as an electrode material for supercapacitors.

\section{Acknowledgements}

This work has been performed with financial support from National Natural Science Foundation of China (No. 51674260, 51274201).

\section{References}

1 P. Simon and Y. Gogotsi, Nat. Mater., 2008, 7, 845.

2 S. Kondrat, C. R. Pérez, V. Presser, Y. Gogotsi and A. A. Kornyshev, Energy Environ. Sci., 2012, 5, 6474.

3 M. R. Lukatskaya, O. Mashtalir, C. E. Ren, Y. Dallagnes, P. Rozier, P. L. Taberna, M. Naguib, P. Simon, M. W. Barsoum and Y. Gogosti, Science, 2013, 341, 1502.

4 K. Kotz and M. Carlen, Electrochim. Acta, 2000, 45, 2483.

5 P. Sivaraman, S. P. Mishra, D. D. Potphode, A. P. Thakur, K. Shashidhara, A. B. Samui and A. R. Bhattacharyya, RSC Adv., 2015, 5, 83546.

6 L. P. Wang, Y. Zhou and J. S. Qiu, Microporous Mesoporous Mater., 2013, 174, 67.

7 L. L. Zhang and X. S. Zhano, Chem. Soc. Rev., 2009, 38, 2520. 8 E. Frackowiak and F. Beguin, Carbon, 2002, 40, 1775.

9 J. Y. Qu, F. Gao, Q. Zhou, Z. Y. Wang, H. Hu, B. B. Li, W. B. Wan, X. Z. Wang and J. S. Qiu, Nanoscale, 2013, 5, 2999.

10 X. Y. Zhang, X. Y. Wang, L. L. Jiang, H. Wu, C. Wu and J. C. Su, J. Power Sources, 2012, 216, 290.

11 D. D. Zhou, Y. J. Du, Y. F. Song, Y. G. Wang, C. X. Wang and Y. Y. Xia, J. Mater. Chem. A, 2013, 1, 1192.

12 S. L. Jin, H. G. Deng, L. Zhan, W. M. Qiao and L. C. Ling, New Res. Carbon Mater., 2012, 27, 87. 
13 W. Lu, S. Huang, L. Miao, M. Liu, D. Zhu, L. Li, H. Duan, Z. Xu and L. Gan, Chin. Chem. Lett., 2017, 28, 1324.

14 L. Miao, H. Duan, M. Liu, W. Lu, D. Zhu, T. Chen, L. Li and L. Gan, Chem. Eng. J., 2017, 317, 651.

15 Y. R. Liang, B. M. Wu, D. C. Wu, F. Xu, Z. H. Li, J. W. Luo, H. Zhong, R. W. Fu and K. Matyjaszewski, J. Mater. Chem., 2011, 21, 14424.

16 W. F. Zhang, Z. H. Huang, G. P. Cao, F. Y. Kang and Y. S. Yang, J. Power Sources, 2012, 204, 230.

17 Y. Luan, Y. W. Xue and Z. G. Shi, Mater. Lett., 2012, 88, 30.

18 J. B. Zhang, L. J. Jin, J. Cheng and H. Q. Hu, Carbon, 2013, 55, 221.

19 G. X. Huang, W. W. Kang, B. L. Xing, L. J. Chen and C. X. Zhang, Fuel Process. Technol., 2016, 142, 1.

20 Z. H. Qin, C. L. Hou, J. Chen, L. Zhang and J. Ma, Int. J. Min. Sci. Technol., 2009, 19, 636.

21 P. Chang and Z. H. Qin, Int. J. Electrochem. Sci., 2017, 12, 1846.

22 B. H. Kim and K. S. Yang, Electrochim. Acta, 2013, 88, 597.

23 D. W. Wang, F. Li, M. Liu, G. Q. Lu and H. M. Cheng, Angew. Chem., Int. Ed., 2008, 47, 373.

24 Y. P. Zhai, Y. Dou, X. X. Liu, S. S. Park, C. S. Ha and D. Zhao, Carbon, 2011, 49, 545.
25 M. Liu, X. Ma, L. Gan, Z. Xu, D. Zhu and L. Chen, J. Mater. Chem. A, 2014, 2, 17107.

26 G. W. Sun, W. H. Song, X. J. Liu, D. H. Long, W. M. Qiao and L. C. Ling, Electrochim. Acta, 2011, 56, 9248.

27 A. Lewandowski, A. Olejniczak, M. Galinski and I. Stepniak, J. Power Sources, 2010, 195, 5814.

28 W. J. Qian, F. X. Sun, Y. H. Xu, L. H. Qiu, C. H. Liu, S. D. Wang and F. Yan, Energy Environ. Sci., 2014, 7, 379.

29 W. F. Zhang, Z. H. Huang, C. J. Zhou, G. P. Cao, F. Y. Kang and Y. S. Yang, J. Mater. Chem., 2012, 22, 7158.

30 F. Gao, G. H. Shao, J. Y. Qu, S. Y. Lv, Y. Q. Li and M. B. Wu, Electrochim. Acta, 2015, 155, 201.

31 J. Y. Qu, C. Geng, S. Y. Lv, G. H. Shao, S. Y. Ma and M. B. Wu, Electrochim. Acta, 2015, 176, 982.

32 X. J. He, Y. J. Geng, J. S. Qiu, M. D. Zheng, S. A. Long and X. Y. Zhang, Carbon, 2010, 48, 1662.

33 H. J. Wang, L. Zhi, K. Q. Liu, L. Q. Dang, Z. H. Liu, Z. B. Lei, C. Yu and J. S. Qiu, Adv. Funct. Mater., 2015, 25, 5420.

34 A. M. Abdelkader, J. Mater. Chem. A, 2015, 3, 8519.

35 M. G. Deng and R. Q. Wang, New Res. Carbon Mater., 2013, $28,262$.

36 X. Li, W. Xing, S. P. Zhuo, J. Zhou, F. Li, S. Z. Qiao and G. Q. Lu, Bioresour. Technol., 2011, 102, 1118. 